important to characterise this level of diagnostic confidence at MDD, thus enabling future research into this patient group.

An emerging recommendation is to manage patients according to their disease behaviour, particularly for the subgroup with ill-defined or overlapping diagnostic features. This should not obviate the imperative to pursue a diagnosis where possible, with appropriate means.

While we accept that there is a group of ILD patients in whom a specific ILD diagnosis is not possible, despite all efforts, we wish to encourage respiratory physicians to pursue an accurate ILD diagnosis, rather than accepting a diagnosis of unclassifiable ILD without full and accurate investigation. Although this is a tempting option, particularly in the absence of ready access to MDD, it is associated with more diagnostic and prognostic uncertainty, and ultimately may delay specific treatment options.

@ERSpublications

Physicians should pursue accurate ILD diagnosis, rather than "unclassifiable ILD" without full investigation http://ow.ly/tt8r0

Lauren Troy ${ }^{1}$, Ian Glaspole ${ }^{2}$, Nicole Goh ${ }^{3}$, Chris Zappala ${ }^{4}$, Peter Hopkins ${ }^{5}$, Margaret Wilsher ${ }^{6}$, Yuben Moodley ${ }^{7}$ and Tamera Corte ${ }^{1}$

${ }^{1}$ Dept of Respiratory and Sleep Medicine, Royal Prince Alfred Hospital, Sydney, ${ }^{2}$ Dept of Allergy, Immunology and Respiratory Medicine, Alfred Health, Melbourne, ${ }^{3}$ Dept of Respiratory and Sleep Medicine, Austin Health, Heidelberg, ${ }^{4}$ Dept of Thoracic Medicine, Royal Brisbane and Women's Hospital, Brisbane, ${ }^{5}$ Lung Transplant Unit, The Prince Charles Hospital, Brisbane, and ${ }^{7}$ Dept of Respiratory Medicine, Royal Perth Hospital, Perth, Australia. ${ }^{6}$ Green Lane Respiratory Services, Auckland City Hospital, Auckland, New Zealand.

Correspondence: L. Troy, Dept of Respiratory and Sleep Medicine, Royal Prince Alfred Hospital, Missenden Rd, Camperdown, Sydney, NSW 2050, Australia. E-mail: ltroy@med.usyd.edu.au

Received: Jan 062014 | Accepted: Jan 092014

Conflict of interest: None declared.

\title{
References
}

Ryerson CJ, Urbania TH, Richeldi L, et al. Prevalence and prognosis of unclassifiable interstitial lung disease. Eur Respir J 2013; 42: 750-757.

2 Travis WD, Costabel U, Hansell DM, et al. An official American Thoracic Society/European Respiratory Society statement: update of the international multidisciplinary classification of the idiopathic interstitial pneumonias. Am J Respir Crit Care Med 2013; 188: 733-748.

3 Latsi PI, du Bois RM, Nicholson AG, et al. Fibrotic idiopathic interstitial pneumonia: the prognostic value of longitudinal functional trends. Am J Respir Crit Care Med 2003; 168: 531-537.

4 Flaherty KR, King TE Jr, Raghu G, et al. Idiopathic interstitial pneumonia: what is the effect of a multidisciplinary approach to diagnosis? Am J Respir Crit Care Med 2004; 170: 904-910.

Cottin V. Significance of connective tissue disease features in pulmonary fibrosis. Eur Respir Rev 2013; 221: 273-280. Raghu G, Anstrom KJ, King TE Jr, et al. Prednisone, azathioprine and $\mathrm{N}$-acetylcysteine for pulmonary fibrosis. N Engl J Med 2012; 366: 1968-1977.

7 Cottin V, Wells A. Unclassified or unclassifiable interstitial lung disease: confusing or helpful disease category? Eur Respir J 2013; 42: 576-579.

\section{Serum CCL18 is predictive for lung disease progression and mortality in systemic sclerosis}

\section{To the Editor:}

We read with pleasure the article "Serum CC chemokine ligand-18 predicts lung disease worsening in systemic sclerosis" [1], published in the European Respiratory Journal. TiEv et al. [1] demonstrated very nicely that elevated CC chemokine ligand 18 (CCL18) serum levels predict lung disease progression in patients with systemic sclerosis (SSc). In the multivariate analysis, the hazard ratio for lung function worsening or death was 5.36 for SSc patients with serum CCL18 concentration above $187 \mathrm{ng} \cdot \mathrm{mL}^{-1}$. They provided clear evidence of this in a French cohort of 83 SSc patients, yet a second affirmation cohort was missing. Recently, 
a)

\begin{tabular}{lccc}
\hline & $\begin{array}{c}\text { Serum CCL18 } \\
<140 \mathrm{ng} \cdot \mathrm{mL}^{-1}\end{array}$ & $\begin{array}{c}\text { Serum CCL18 } \\
>140 \mathrm{ng} \cdot \mathrm{mL}^{-1}\end{array}$ & $\mathrm{p}$-value \\
\hline Age years & 52.7 & 55.0 & $\mathrm{NS}$ \\
Sex female/male $\mathrm{n}$ & $65 / 16$ & $7 / 8$ & $<0.05$ \\
Body weight kg & 66.7 & 64.1 & $\mathrm{NS}$ \\
Body height m & 1.68 & 1.65 & $\mathrm{NS}$ \\
Baseline FVC\% & 87.0 & 77.4 & $\mathrm{NS}$ \\
Baseline FEV1\% & 88.2 & 81.0 & $\mathrm{NS}$ \\
Baseline DLC0,SB\% & 59.2 & 48.0 & $<0.05$ \\
PAH\% & 32.1 & 46.7 & $\mathrm{NS}$ \\
\hline
\end{tabular}

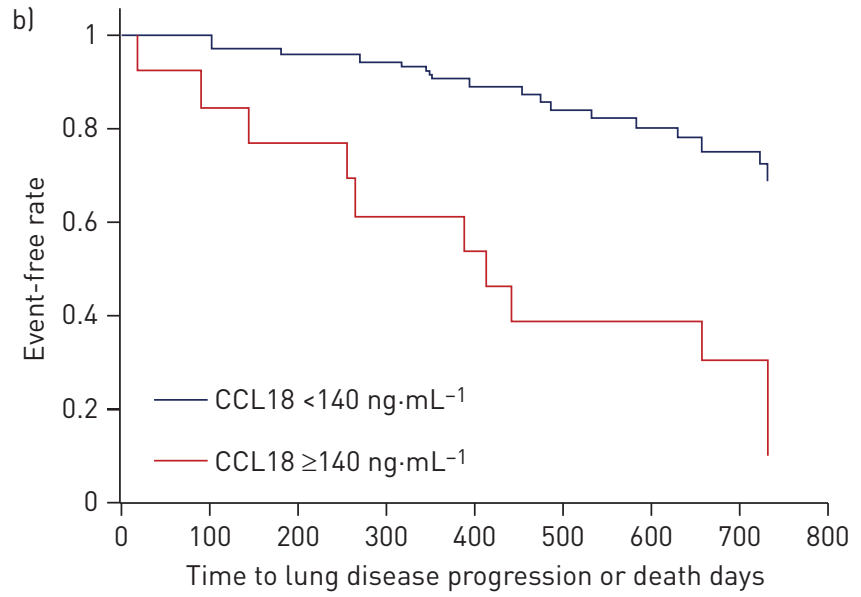

FIGURE 1 a) Basic patient characteristics. Data are presented as mean, unless otherwise stated. FVC: forced vital capacity; FEV1: forced expiratory volume in 1 s; DLCO,SB: single-breath diffusing capacity of the lung for carbon monoxide; PAH: pulmonary arterial hypertension; ns: not significant. b) Kaplan-Meier Survival

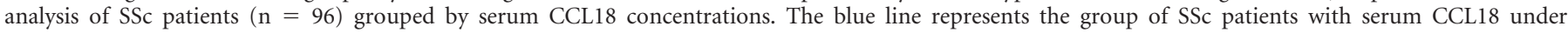
$140 \mathrm{ng} \cdot \mathrm{mL}-1$ and the red line represents the group of SSc patients with over $140 \mathrm{ng} \cdot \mathrm{mL}-1$, respectively.

ELHAJ et al. [2] showed a rather weak correlation of CCL18 levels with changes in forced vital capacity (FVC) over time studying a large cohort of early SSc patients, but failed to analyse lung function data in regards to progression of SSc-associated interstitial lung disease (ILD) accordingly to European Respiratory Society (ERS) consensus. Moreover, neither cut-off values for CCL18 levels nor hazard ratios were reported by the authors. Thus, the results of TIEv et al. [1] still need to be validated in a second, independent cohort.

Systemic sclerosis (SSc) is a multi-organ connective tissue disease, in which heart and lung involvements are the most common causes of death. Published 10-year survival rates vary between 55\% and 77\% [3]. New therapies as well as new biomarkers, reflecting disease activity and prognosis, are therefore urgently needed.

Fibrotic lung diseases are characterised by a distinct macrophage activation type called alternative or M2 [4]. M2 macrophages are key players in wound healing, fibrosing processes and are similar to tumourassociated macrophages (TAMs) [5]. CCL18 is mainly secreted by human myeloid cells, especially by macrophages [6] and is one of the most important human markers of alternatively activated macrophages. Elevated CCL18 levels are described in various fibrotic diseases of the lung, e.g. systemic sclerosis and idiopathic interstitial pneumonias [7], especially idiopathic pulmonary fibrosis [8].

To determine the predictive relevance of serum CCL18, we correlated CCL18 with pulmonary function tests and survival data in a German cohort of 96 patients with SSc. SSc diagnosis was established according to American College of Rheumatology criteria [9]. All included SSc patients attended the outpatient clinic of the tertiary referral centre at the University hospital Charite Berlin, Germany, and were followed-up for 2 years. The study was approved by the local ethics committee. During routine check-up (at least once a year), pulmonary function tests were performed, according to the American Thoracic Society (ATS) recommendations using a body plethysmograph. A decline of more than $10 \%$ predicted in forced vital capacity compared with baseline was considered a significant decline, corresponding to the ATS/ERS criteria [10]. To quantify CCL18 serum concentrations, we used the DuoSet ELISA Development System Kit (R\&D Systems Europe, UK) pursuant to manufacturer's protocol. CCL18 cut-off values were established using receiver operating characteristic curves comparing the areas under the curve. We computed KaplanMeier curves and performed (univariate and multivariate) Cox proportional hazards models to analyse the influence of CCL18 on time to lung function worsening, defined as decline of the predicted forced vital capacity (FVC), $10 \%$ or death.

Our results were as follows. Basic patient's characteristics are displayed in figure 1a. On average, baseline serum CCL18 concentration was $101 \pm 62 \mathrm{ng} \cdot \mathrm{mL}^{-1}$ and ranged from $27 \mathrm{ng} \cdot \mathrm{mL}^{-1}$ to $421 \mathrm{ng} \cdot \mathrm{mL}^{-1} \cdot 15$ patients died during follow up. The optimal cut-off for baseline serum CCL18 concentration was $140 \mathrm{ng} \cdot \mathrm{mL}^{-1}$, based on the maximal area under the curve in the receiver operating characteristic analysis. 15 SSc patients had a serum concentration above $140 \mathrm{ng} \cdot \mathrm{mL}^{-1}$. SSc patients with serum CCL18 concentrations above $140 \mathrm{ng} \cdot \mathrm{mL}^{-1}$ did not significantly differ from SSc patients with concentrations lower than $140 \mathrm{ng} \cdot \mathrm{mL}^{-1}$ in age, body weight and height, baseline FEV1 or in baseline FVC, but significantly in sex and single-breath diffusing capacity of the lung for carbon monoxide. SSc patients with CCL18 levels above $140 \mathrm{ng} \cdot \mathrm{mL}^{-1}$ had a significantly higher risk for death or lung function worsening $(\mathrm{p}<0.0001)$ within 2 years 
than SSc patients with low CCL18 levels. The Kaplan-Meier curve is depicted in figure 1b. The hazard ratio to suffer from death or progression of SSc-associated ILD was 4.8 in the univariate Cox hazard model and 5.1 in the multivariate Cox hazard model (after adjusting for age, sex, baseline FVC, body weight and height), respectively.

In conclusion, we were able to confirm in a second independent cohort, that serum CCL18 concentration is a significant predictor of mortality and progression of ILD in patients with SSc. This holds true even after adjusting for physiological parameter. The optimal CCL18 cut-off value in our cohort was $140 \mathrm{ng} \cdot \mathrm{mL}-1$ and hence lower compared to the $187 \mathrm{ng} \cdot \mathrm{mL}-1$ determined by Tiev et al, maybe due to technical differences in CCL18 measurement. However, the hazard ratios of the univariate $(H R=4.8$ vs. 5.4$)$ and the multivariate $(\mathrm{HR}=5.1$ vs. 5.4$)$ analysis were very similar. This demonstrates that, in scleroderma, CCL18 has the potential to become a major biomarker for clinical evaluation, therapy planning and stratification in clinical trials.

\section{0} @ERSpublications

Serum CCL18 is predictive for lung disease progression and mortality in systemic sclerosis http://ow.ly/ugkrH

Jonas Schupp ${ }^{1}$, Mike Becker ${ }^{2}$, Jeannine Günther ${ }^{2}$, Joachim Müller-Quernheim ${ }^{1}$, Gabriela Riemekasten ${ }^{2}$ and Antje Prasse

${ }^{1}$ Dept. of Pneumology, Medical Centre, University Hospital Freiburg, Freiburg, Germany, and ${ }^{2}$ Dept. of Rheumatology and Clinical Immunology, University Hospital Charité Berlin, Berlin, Germany.

Correspondence: J. Schupp, Dept. of Pneumology, Medical Centre, University Hospital Freiburg, Freiburg, Germany. E-mail: Jonas.Schupp@uniklinik-freiburg.de

Received: July 302013 | Accepted after revision: Sept 172013

Conflict of interest: None declared.

Acknowledgements: The authors would like to thank N. Wehrle and S. Kamenker (Dept of Pneumology, Medical Centre, University Hospital Freiburg, Germany) for skilful technical assistance.

\section{References}

1 Tiev KP, Hua-Huy T, Kettaneh A, et al. Serum CC chemokine ligand-18 predicts lung disease worsening in systemic sclerosis. Eur Respir J 2011; 38: 1355-1360.

2 Elhaj M, Charles J, Pedroza C, et al. Can serum surfactant protein D or CC-chemokine ligand 18 predict outcome of interstitial lung disease in patients with early systemic sclerosis? J Rheumatol 2013; 40: 1114-1120.

3 Mayes MD, Lacey JV, Beebe-Dimmer J, et al. Prevalence, incidence, survival, and disease characteristics of systemic sclerosis in a large US population. Arthritis Rheum 2003; 48: 2246-2255.

4 Stein M, Keshav S, Stein BM, et al. Interleukin 4 potently enhances murine macrophage mannose receptor activity: a marker of alternative immunologic macrophage activation. Receptor 1992; 176: 287-292.

5 Mantovani A, Sica A, Sozzani S, et al. The chemokine system in diverse forms of macrophage activation and polarization. Trends Immunol 2004; 25: 677-686.

6 Schraufstatter I, Takamori H, Sikora L, et al. Eosinophils and monocytes produce pulmonary and activationregulated chemokine, which activates cultured monocytes/macrophages. Am J Physiol Lung Cell Mol Physiol 2004; 286: L494-L501.

7 Prasse A, Pechkovsky DV, Toews GB, et al. CCL18 as an indicator of pulmonary fibrotic activity in idiopathic interstitial pneumonias and systemic sclerosis. Arthritis Rheum 2007; 56: 1685-1693.

8 Prasse A, Pechkovsky DV, Toews GB, et al. A vicious circle of alveolar macrophages and fibroblasts perpetuates pulmonary fibrosis via CCL18. Am J Respir Crit Care Med 2006; 173: 781-792.

9 Preliminary criteria for the classification of systemic sclerosis (scleroderma). Subcommittee for scleroderma criteria of the American Rheumatism Association Diagnostic and Therapeutic Criteria Committee. Arthritis Rheum 1980; 23: $581-590$.

10 American Thoracic Society/European Respiratory Society International Multidisciplinary Consensus Classification of the idiopathic interstitial pneumonias. Am J Respir Crit Care Med 2002; 165: 277-304. 